Federal Reserve Bank of Dallas

Globalization and Monetary Policy Institute

Working Paper No. 115

http://www.dallasfed.org/assets/documents/institute/wpapers/2012/0115.pdf

\title{
Does Foreign Exchange Intervention Volume Matter? *
}

\author{
Rasmus Fatum \\ University of Alberta \\ Yohei Yamamoto \\ Hitotsubashi University
}

May 2012

\begin{abstract}
We investigate whether foreign exchange intervention volume matters for the exchange rate effects of intervention. Our investigation employs daily data on Japanese interventions from April 1991 to April 2012 and time-series estimations, non-temporal threshold analysis, as well as binary choice models. We find that intervention volume matters for the effects of intervention, but only to the extent that the exchange rate effect per intervention unit is magnified in a linear sense by the larger intervention amount. This is a policy-relevant finding that also adds to our understanding of how intervention works.
\end{abstract}

JEL codes: E52, F31, G14

\footnotetext{
* Rasmus Fatum, School of Business, University of Alberta, 4-30H Business Building, Edmonton, Alberta, Canada T6G 2R6. 780-492-3591. Rasmus.fatum@ualberta.ca. Yohei Yamamoto, Hitosubashi University, 2-1 Naka, Kunitachi, Tokyo 186-8601, Japan. 81-42-580-8000. Yohei.yamamoto@econ.hit-u.ac.jp. Fatum gratefully acknowledges financial support from Social Sciences and Humanities Research Council of Canada (SSHRC). We thank seminar participants at the Asian Development Bank Institute and the Bank of Japan, as well as Kathryn Dominguez, Michael Hutchison, and Barry Scholnick, for very helpful comments. We also thank Liberty Hull, Priya Kalandasani, and Mark Zschocke for outstanding research assistance. The views in this paper are those of the authors and do not necessarily reflect the views of the Federal Reserve Bank of Dallas or the Federal Reserve System.
} 


\section{Introduction}

We investigate whether foreign exchange intervention volume matters for the exchange rate effects of intervention. ${ }^{1}$ Our investigation employs two decades of daily data on Japanese interventions as well as time-series estimations, non-temporal threshold analysis, and binary choice models. ${ }^{2}$ Whether intervention volume matters is an issue of interest to authorities with a mandate to intervene as knowledge regarding the volume effects of intervention is necessary to make an informed decision regarding the amount with which to intervene. It is also an issue of academic interest since an understanding of the influence of intervention volume on the exchange rate effect of intervention may shed light on how intervention works. We find that intervention volume matters for the effects of intervention, but only to the extent that the exchange rate effect per intervention unit is magnified in a linear sense by the larger intervention amount.

The existing empirical evidence regarding the extent to which intervention volume matters is mixed. Dominguez and Frankel (1993) show that central bank market presence rather than intervention volume can at times fully explain the exchange rate effects of intervention, thereby implying that intervention volume may not matter at all. Other studies find that only large interventions are effective while smaller interventions are ineffective or even counterproductive, thereby implying that the exchange rate effects of intervention volume are non-linear and discontinuous (e.g. Beine and Szafarz, forthcoming, and Fatum and Hutchison, 2006).

\footnotetext{
${ }^{1}$ This is a particularly topical issue in light of the recent Japanese interventions of unprecedented proportions where three of the four largest daily interventions over the past two decades have occurred since Japan unexpectedly resumed an active intervention policy in September 2010. Notably, on 31 October 2011 the Japanese monetary authorities sold JPY in the USD/JPY market in the amount of more than USD 100 billion. By far, the volume of this intervention operation exceeds any other intervention on record.

${ }^{2}$ Humpage (2003), Neely (2005), and Sarno and Taylor (2001) provide surveys of the intervention literature. Beine et al. (2007), Chen et al. (2009), Fatum and Hutchison (2006), Ito (2003, 2005), Iwata and Wu (2008), Kim and Sheen (2006), Marsh (2011) and others study the effects of intervention in the USD/JPY market.
} 
Typically, the relative importance of large interventions is assessed by imposing arbitrary volume thresholds to define large interventions. In the context of time-series studies, the exchange rate models include large-volume intervention dummies or separate variables for larger and smaller interventions. In the context of event studies, the exchange rate effects of intervention are assessed separately across sub-samples of larger and smaller interventions. These approaches are problematic for two reasons. First, since intervention volume tends to increase over time, testing the relevance of the arbitrary volume threshold really amounts to a test of whether more recent interventions are more effective on average than interventions carried out a longer time ago. ${ }^{3}$ Second, a more fundamental concern is the fact that the threshold is imposed rather than identified and the results may thus depend on the chosen threshold.

The contribution of our paper is to bring clarity to the unresolved issue of whether intervention volume matters. We do so by analyzing daily data on Japanese interventions spanning the two decades from April 1991 to April 2012. First, we use time-series techniques (GARCH models) to address whether intervention volume matters at all or if central bank presence alone can explain the associated day-to-day changes in the level of the USD/JPY spot rate. We then follow the standard approach of the intervention literature and test whether larger interventions are associated with different exchange rate effects by imposing a reasonable but nevertheless arbitrary volume threshold. While this part of our analysis is subject to the aforementioned criticism regarding arbitrariness in the choice of threshold, we carry out the investigation by testing sample-specific intervention volume thresholds across previously identified sub-samples, thereby ensuring that the thresholds are not effectively postulated timeseries breakpoints. We also test for continuous non-linearities within the context of our time-

\footnotetext{
${ }^{3}$ In the context of Japanese interventions, where Ito (2003) and others have found intervention to be ineffective until the mid-1990s, this seems a particular concern.
} 
series framework. To address the fundamental concern regarding the arbitrariness of the imposed volume threshold we employ the non-temporal breakpoint analysis proposed by Hansen (2000). Doing so allows us to formally test whether intervention volume thresholds are present in our data without having to assume what such threshold levels might be.

Other studies suggest that intervention volume is not the only possible determinant for whether or not an intervention operation is effective in influencing the daily exchange rate change in a manner consistent with the intervention (e.g. Humpage 1999). We thus complement our time-series estimations of volume effects and volume thresholds with a broader assessment of whether intervention volume along with other possible intervention characteristics such as intervention frequency, market awareness of intervention, and coordination of intervention across central banks, influence the success of intervention.

Our time-series results show that intervention volume matters to the extent that larger interventions are associated with larger exchange rate movements. However, our results also show that larger interventions are no more effective than smaller interventions in an exchange rate effect per unit of intervention sense. Our threshold analysis finds no indication of systematic structural breaks associated with intervention volume. Our logit model estimations show that intervention volume is the best predictor of intervention success, consistent with the beliefs of central bankers. ${ }^{4}$

There is a mapping from intervention volume to how intervention works. If intervention volume is unimportant and the exchange rate effect of intervention stems solely from the central bank being present in the foreign exchange market, the effects of intervention cannot be explained by the portfolio-balance channel since this intervention transmission channel implies

\footnotetext{
${ }^{4}$ Neely (2008) reports that 17 of the 22 central bankers responding to his survey agree or strongly agree that larger interventions increase the probability of a successful intervention.
} 
that the effects of interventions are linear in volume at least during time-periods where the exchange rate risk premium is constant. Consequently, if intervention volume is unimportant, intervention works through other channels such as the signaling channel or the coordination channel. ${ }^{5}$ For the same reason, if intervention volume matters for the exchange rate effect of intervention but the effects of intervention are non-linear in intervention volume, the effects of intervention cannot be fully explained by the portfolio-balance channel. By contrast, only if the effects of intervention are linear in intervention volume are the effects consistent with the portfolio-balance channel.

Overall, our results show that intervention volume matters, but only to the extent that the exchange rate effect per intervention unit is magnified in a linear sense by the larger intervention amount. Since intervention volume matters and non-linearities are absent, our results seem consistent with the portfolio-balance channel.

The rest of the paper is organized as follows. Section 2 summarizes the data. Section 3 details the empirical methods. Section 4 presents the results. Section 5 concludes.

\footnotetext{
${ }^{5}$ The portfolio balance channel relies on foreign and domestic assets (bonds) being imperfect substitutes in which case the intervention induced change in the relative supplies of these assets is accompanied by a corresponding change in relative asset returns in order for investors to be willing to hold both foreign and domestic assets. The portfolio balance channel then suggests that the change in relative asset returns, in the absence of changes in relative nominal interest rates, is generated by an adjustment of the current exchange rate. The signaling channel hypothesis suggests that by carrying out intervention the central bank informs the market, or sends a signal, about its future policy intentions. The coordination channel pertains to a situation of substantial exchange rate misalignment and coordination failure to the extent that individual market participants are hesitant to risk betting on a reversal of the exchange rate towards its equilibrium. In such a situation the coordination channel proposes that detected or publicly announced intervention can take on a coordinating role that organizes fundamentalist traders to enter the market at the same time, thereby causing the exchange rate to adjust. For additional details on transmission channels see, for example, Sarno and Taylor (2001).
} 


\section{Data}

The intervention data consist of official daily volumes of all intervention operations carried out by the Japanese and US monetary authorities in the USD/JPY foreign exchange market between 1 April 1991 and 25 April 2012. ${ }^{6}$

Table 1 provides intervention data summary statistics for the full sample period as well as separately across three sub-samples (the identification of sub-samples is discussed in detail in Section 4). The first column of Table 1 shows that during the two decades under study intervention in the USD/JPY market occurred on a total of 352 days. For the full sample period, the daily intervention amount ranges from USD 1 million to USD 103 billion, and the average intervention amount is USD 2.4 billion. Columns two through four show that the average intervention amount and frequency vary dramatically across the three sub-samples. During the first four years under study, the average intervention amount across 165 intervention days is close to USD 0.5 billion. Between May 1995 and March 2004, intervention occurred on 179 days in the average amount of USD 3.0 billion. During the last sub-sample, the September 2010 to April 2012 period, intervention is carried out on eight days in the average amount of USD 26 billion.

All interventions under study are either unilateral Japanese interventions or coordinated in the sense that both Japan and the US are intervening in the USD/JPY market on the same day and in the same direction. The second-last row of Table 1 reports the number of coordinated intervention days across the full sample and across the sub-samples. As the row shows, a total of

\footnotetext{
${ }^{6}$ See Bordo, Humpage, and Schwartz (2011) and Ito (2005), respectively, for descriptions of the US and the Japanese institutional framework for intervention.
} 
23 intervention days are coordinated, and 22 of these coordinated interventions occur during the first two sub-samples. ${ }^{7}$

The last row of Table 1 shows the number of detected intervention days, i.e. interventions that occur on a day when there is a rumor of intervention on the newswire. The full April 1991 to April 2012 sample encompasses a total of 214 detected interventions, amounting to roughly $60 \%$ of the interventions in the sample. ${ }^{8}$

The daily exchange rate data consist of New York close USD/JPY spot market quotes obtained from Global Financial Data (GFD). ${ }^{9}$ Exchange rate summary statistics are detailed in Table 2. The first row of this table shows that over the course of the two decades under study the USD depreciated from $0.00713 \mathrm{USD} / \mathrm{JPY}$ at the start of the sample to $0.01229 \mathrm{USD} / \mathrm{JPY}$ at the end of the sample, a total USD depreciation against the JPY of $72 \%$.

The analysis controls for macro surprises of Japanese news regarding CPI, GDP, industrial production, trade balance, unemployment and US news regarding CPI, GDP, industrial production, trade balance, non-farm payroll employment, and monetary policy. For each of these news variables, the surprise is measured as the difference between the official announcement and the result of surveys of expectations of the announcement conducted by Bloomberg during the days preceding the announcement. The official value of a news variable is announced once a month, or at a lower frequency. The news control variables capture the associated surprise element on announcement dates, thus these variables are non-zero only on announcement dates

\footnotetext{
${ }^{7}$ The only coordinated USD/JPY intervention day for more than a decade occurred in March 2011 in response to the sudden JPY appreciation following the 9.0 earthquake in Japan on 11 March 2011. This particular coordinated intervention driven by very unusual circumstances is described in detail in Neely (2011).

${ }^{8}$ The Factiva search engine and a comprehensive combination of various English language search words (e.g. Bank of Japan, intervention etc.) are used to find the days with a rumor of intervention. Detected intervention is sometimes referred to as "public intervention", while undetected intervention is sometimes referred to as "secret intervention". For additional details regarding detected versus undetected interventions in the USD/JPY market see Beine and Bernal (2007), Fatum (2010), and Kim and Le (2010).

${ }^{9}$ See Ito (2003) for a detailed explanation regarding the necessity of using New York close quotes in daily data studies of intervention in USD/JPY market.
} 
and only when the announcement differs from market expectations. Macro news data summary statistics are available from the authors upon request.

\section{Empirical Analysis}

The empirical analysis consists of three parts. The first part of the analysis follows Baillie and Bollerslev (1989) and others in estimating time-series regression models of the daily change in the USD/JPY exchange rate with GARCH residuals. The objective of these estimations is to assess if the exchange rate effects of intervention can be explained by central bank market presence alone, if the exchange rate effect of large interventions defined as mean (absolute) intervention volume plus one standard deviation are different from those of smaller interventions, and if the exchange rate effects of interventions are better captured by inclusion of a quadratic intervention term. The estimated models are described by the following general $\operatorname{GARCH}(\mathrm{p}, \mathrm{q})$ specification:

$$
\begin{aligned}
& \text { (1) } \Delta s_{t}=a+b_{1} \Delta s_{t-1}+b_{2} \text { INTVOL }_{t}+b_{3} \text { INTINDIC }_{t}+b_{4} \text { LTMSTD }_{t}+b_{5} \text { SIGNQ }_{t}+C Z_{t}+\varepsilon_{t} \\
& \text { (2) } \varepsilon_{t} \sim N\left(0, h_{t}\right) \\
& \text { (3) } h_{t}=\alpha_{0}+\sum_{j=1}^{q} \alpha_{j} \varepsilon_{t-j}^{2}+\sum_{j=1}^{p} \beta_{j} h_{t-j}
\end{aligned}
$$

where a is a constant; $\Delta s_{t}$ is the first-difference in the log of the spot USD/JPY exchange rate; INTVOL $_{t}$ is official intervention volume (millions of USD); INTINDIC $\mathrm{t}_{\mathrm{t}}$ is a signed indicator variable that takes on the value one on days with intervention purchases of USD, minus one on days with intervention sales of USD, and zero otherwise; $\operatorname{LTMSTD}_{t}$ is a sample-specific 
interaction variable ("slope shifter") containing interventions (millions of USD) larger than the mean absolute intervention volume plus one standard deviation (millions of USD); SIGNQ $_{t}$ is an interaction variable containing squared interventions (millions of USD) multiplied by INTINDIC $;$; is the coefficient vector associated with the control variables contained in $\mathrm{Z}_{\mathrm{t}}$. The control variable matrix $Z_{t}$ contains the surprise component of the macro news described in Section $2 .{ }^{10}$ Equation (2) states that the error term is normally distributed with zero mean and time-dependant (conditional) variance $h_{t}$. Equation (3) shows that the variance depends on the squared error of the past q periods (the ARCH terms) and the conditional variance of the past $\mathrm{p}$ periods. ${ }^{11,12}$

The second part of the analysis employs a threshold analysis proposed by Hansen (2000) to assess if intervention volume matters without imposing any priors in regards to what might constitute large volume intervention. The estimated equations take the following form:

$$
\Delta s_{t}=a_{H 1}+b_{H 1} \Delta s_{t-1}+b_{H 1} I N T V O L_{t}+\varepsilon_{H 1 t} \quad \text { if } \text { ABSINTVOL }_{t} \leq \gamma
$$

$$
\Delta s_{t}=a_{H 2}+b_{H 2} \Delta s_{t-1}+b_{H 2} I N T V O L_{t}+\varepsilon_{H 2 t}
$$

if ABSINTVOL $_{t}>\gamma$

\footnotetext{
${ }^{10}$ The four intervention variables are, of course, all positively correlated. Consequently, we do not estimate the full conditional mean equation with all four intervention variables included simultaneously. Instead, our baseline estimation follows Ito (2003) and includes only the intervention variable INTVOL . $_{\text {. }}$

${ }^{11}$ Consistent with Fatum and Scholnick (2006) and other daily data studies of the USD/JPY exchange rate we find the $\operatorname{GARCH}(1,1)$ specification to provide the best and most parsimonious data fit.

${ }^{12}$ Endogeneity is generally a major concern in studies of the exchange rate effects of intervention (and we do attempt to formally address this concern in our robustness section). However, as long as any simultaneity bias is reasonably uniform across the interventions under study, endogeneity is a limited concern when the objective is to assess the relative importance of different intervention volumes rather than to obtain precise estimates of the exchange rate effects of intervention.
} 
where ABSINTVOL $_{t}$ is the absolute value of INTVOL $_{t}$, and $\gamma$ is a threshold value to be estimated by the maximand of the likelihood ratio statistics over all permissible threshold values. ${ }^{13}$ The testing procedure is similar to the standard temporal parameter change test for unknown breakpoint (e.g. Andrews 1993). However, instead of analyzing a temporally-ordered data set, we sort the data according to the absolute value of the variable INTVOL . This sorting procedure makes the absolute value of INTVOL $_{t}$ the trending variable and, consequently, the asymptotic distribution of the standard temporal change-point test is not reliable. Therefore, our threshold test results are based on the $p$-values computed by the asymptotically correct bootstrap procedure proposed by Hansen (2000). ${ }^{14,15}$

The third part of the analysis provides an assessment of whether intervention volume and other possible intervention characteristics such as intervention frequency, market awareness of intervention, and coordination of intervention across central banks determine the success of intervention. To do so we follow Humpage (1999) in estimating binary choice models of success of intervention using the aforementioned possible success determinants as explanatory variables in conjunction with the two definitions of what constitutes an intervention success proposed by Fatum and Hutchison (2003). The first definition of success is denoted the direction criterion. It labels an intervention a success if either $\left\{\mathrm{INTVOL}_{\mathrm{t}}>0\right.$ and $\Delta s_{t}<0$ or $\mathrm{INTVOL}_{\mathrm{t}}<0$ and $\Delta s_{t}>$

\footnotetext{
${ }^{13}$ The parameter $\gamma$ is assumed to be within the bounded set [0.001N, $\left.0.999 \mathrm{~N}\right]$ where $N$ denotes the sample size.

${ }^{14}$ Ordering the data as described ignores potential serial correlations in the errors thus the computed standard errors may be under-estimated. To address this concern we include in our regression models lags of the dependent variable as additional explanatory variables. To make sure that the residuals of the final regression do not exhibit serial correlations, we first estimate the threshold parameter and the coefficients estimates to obtain the residuals. We then re-order the residuals temporally and perform the test for serial correlations using the re-ordered residuals. As it turns out, including only the first lag of the dependent variable is sufficient to ensure that the errors are free of serial correlation. The GARCH character of the residuals is accounted for using the heteroskedasticity robust standard errors of White (1980).

${ }^{15}$ As noted earlier, endogeneity is a limited concern when assessing the relative importance of different intervention volumes. In the specific context of our threshold analysis, it is additionally reassuring that Perron and Yamamoto (2011) show that a SupWald test and, by implication, a SupLR test can detect parameter instability in OLS models even in the presence of endogeneity.
} 
$0\}$. The second definition of success is denoted the smoothing criterion. It labels an intervention a success if either \{intervention is a success according to the direction criterion $\}$ or $\left\{\right.$ abs $\Delta s_{t}<$ $\left.\operatorname{abs} \Delta s_{t-1}\right\} .{ }^{16}$ Separately applying these two success criteria to each intervention day in our sample produces two binary variables that facilitate the estimation of the following logit models:

$$
\begin{aligned}
& D_{l}=a_{D}+b_{D 1} \Delta s_{l-1}+b_{D 2} \text { ABSINTVOL }_{l}+b_{D 3} \text { DSLI }_{l}+b_{D 4} \text { DETECT }_{l}+b_{D 5} \text { COORD }_{l}+\varepsilon_{D l} \\
& S_{l}=a_{S}+b_{S 1} \Delta s_{l-1}+b_{S 2} \text { ABSINTVOL }_{l}+b_{S 3} \text { DSLI }_{l}+b_{S 4} \text { DETECT }_{l}+b_{S 5} \text { COORD }_{l}+\varepsilon_{S l}
\end{aligned}
$$

where $D_{1}\left(S_{1}\right)$ takes on the value one when intervention is a success according to the direction (smoothing) criterion and zero otherwise; $\mathrm{ABSINTVOL}_{1}$ is the absolute value of intervention (millions of USD); DSLI $_{1}$ is a continuous variable that counts the number of business days since the last intervention occurred; $\mathrm{DETECT}_{1}$ is an indicator variable that takes on the value one when an intervention day coincides with a same-day rumor of intervention and zero otherwise; $\mathrm{COORD}_{1}$ is an indicator variable that takes on the value one when both Japan and the US are intervening in the USD/JPY market on the same day and in the same direction and zero otherwise.

\section{Results}

Our starting point is to estimate the time-series model described in Equations (1) through (3) across the full April 1991 to April 2012 sample with only the constant, the first lag of the daily

\footnotetext{
${ }^{16}$ As noted by Fatum and Hutchison (2003), both success criteria are problematic if intervention is "leaning with the wind", i.e. if intervention sales (purchases) of USD occur when the, in our context, previous-day exchange rate change is a USD depreciation (appreciation). We address this concern with a robustness check that excludes leaning with the wind interventions.
} 
exchange rate change, intervention volume, and the macro control variables included in the conditional mean model. This is our baseline model. The first column of Table 3 reports the results. The column shows the intervention volume variable is highly significant and of the correct sign, i.e. an intervention purchase (sale) of USD is, on average, systematically associated with a same-day appreciation (depreciation) of the USD vis-à-vis the JPY. ${ }^{17}$

Before we proceed, we need to take into account the possibility of structural breaks. The fact that $6 \frac{1}{2}$ years of no intervention occurred between March 2004 (when what Taylor 2006 and others refer to as the "great intervention" ended abruptly) and September 2010 (when Japan suddenly resumed an active intervention policy against the backdrop of the current global financial crisis) suggests that interventions that occurred since 2010 should be considered separately. ${ }^{18}$ To consider the possibility of parameter instability over the 1991 to 2004 timeperiod we employ the Bai and Perron (1998) structural change test for multiple unknown breakpoints. ${ }^{19,20}$ We first consider the possibility of a single break. The testing procedure identifies 05 May 1995 as a structural break with 99\% significance (Sup $F=13.98) .{ }^{21}$ Next, we carry out the sequential testing procedure to address whether additional breaks are present. We first test the possibility of one break against two breaks. The test statistic associated with the possibility of two breaks is only marginally significant $(\operatorname{Sup} F(2 \mid 1)=8.38)$. The two break dates

${ }^{17}$ The first lag of the daily exchange rate is insignificant in all estimations, as are most of the macro control variables. This is not surprising in our context of daily frequency exchange rate modeling. For brevity, we thus do not report the coefficient estimates associated with the lagged exchange rate change and the macro controls.

${ }^{18}$ Fawley and Juvenal (2010) discuss in detail the 15 September 2010 intervention that constitutes the return of Japan to an active intervention policy.

${ }_{19}$ We estimate the previously described baseline model and test the null hypothesis of the intervention volume coefficient estimate being time-independent versus the alternative of structural changes in said coefficient estimate across all permissible break points. To perform the tests, heteroskedasticity and autocorrelation consistent variance (HAC) are used with Andrews (1991) data dependent method with quadratic spectral kernel and bandwidth chosen by AR(1) approximation. Consistent with the literature standard we set the truncation parameter that defines the permissible break dates to 0.15 .

${ }^{20}$ It is not meaningful to apply the Bai and Perron (1998) test for multiple breaks to the full April 1991 to April 2012 sample since the 2010 to 2011 interventions would occur after any reasonable break date, e.g. a break date of 0.15.

${ }^{21}$ This breakpoint date is largely consistent with Ito (2003) who imposes 21 June 1995, when Mr. Sakakibara took office as Vice Minister for International Affairs at the Japanese Ministry of Finance, as a structural break date. 
are identified as 08 May 1995 and 26 September $2001 .^{22}$ The test statistics associated with additional breaks are not significant. In sum, we find strong evidence of a single break in early May 1995 while the evidence to support the presence of a second break in September 2001 is much weaker.

Columns three through five of Table 3 display the results of estimating the baseline model separately across the previously identified sub-samples. ${ }^{23}$ The third column shows that intervention was not effective in influencing the same-day exchange rate change during the 1991 to 1995 period (the intervention volume variable is significant but of the wrong sign). ${ }^{24}$ The fourth column shows that intervention during the 1995 to 2004 period was effective on average (the intervention volume variable is significant and of the correct sign). ${ }^{25}$ The fifth column shows that the coefficient estimate associated with the most recent interventions is also highly significant and of the correct sign, indicating that these recent intervention sales of JPY were systematically associated with a JPY depreciation.

\subsection{Time Series Analysis of Intervention Volume Effects}

As a preliminary assessment of the extent to which intervention volume matters we first test if the estimated exchange rate effect per intervention unit since September 2010 is different than the average effect per intervention unit during the earlier periods of relatively smaller intervention volumes. To do so we employ coefficient restriction t-tests. ${ }^{26}$ Specifically, we

\footnotetext{
${ }^{22}$ These dates are identified by the dynamic programming procedure described in Bai and Perron (1998). The date of the first of two breaks does not necessarily coincide with the date identified by the single break test.

${ }^{23}$ We consider the possibility of the September 2001 breakpoint in our robustness section.

${ }^{24}$ The 1991 to 1995 ineffectiveness result is also found in Ito (2003).

${ }^{25}$ The 1995 to 2004 effectiveness result is consistent with Fatum (2010), Fatum and Hutchison (2006), Iwata and $\mathrm{Wu}(2008)$ and others.

${ }^{26}$ The t-statistic for the null of symmetry across two estimations is given by the coefficient estimate difference divided by the square root of the sum of the squared standard deviations. For additional details see, for example, Anderson et al. (2010).
} 
compare the September 2010 to April 2012 intervention volume coefficient estimate separately to the 1991 to 2004,1991 to 1995 , and 1995 to 2004 intervention volume coefficient estimates reported in columns two through four of Table 3 . The bottom rows of the fifth column of Table 3 reports the t-stats and shows that only when comparing to the 1991 to 1995 period (where intervention is ineffective and the intervention volume coefficient estimate is of the wrong sign) can we statistically reject equality of coefficients. In other words, the estimated per intervention unit effect of the recent interventions appears no different than the one associated with interventions carried out between 1995 and 2004, despite the fact that the average daily intervention amount during the most recent sub-sample is more than 8 times larger than that of the 1995 to 2004 sub-sample.

To assess whether intervention central bank presence alone can explain the same-day exchange rate effects of intervention we re-estimate Equations (1) through (3) after including the intervention indicator variable in the conditional mean expression of our baseline model. The results are reported in Table 4. The first column shows that for the 1991 to 1995 sample, both the intervention volume variable and the intervention indicator variable coefficient estimates are of the wrong sign, and only the former variable is significant. For the 1995 to 2004 estimations, the second column shows that the intervention volume variable is highly significant and of the correct sign (consistent with the baseline estimation) while the indicator variable is highly insignificant and of the wrong sign. Clearly, these results imply that central bank presence alone cannot explain the exchange rate effects of intervention.

As noted earlier, the existing intervention literature addresses whether larger-volume interventions influence the exchange rate differently and in a non-linear sense by testing the statistical significance of large-volume thresholds. In this section we follow this literature by 
estimating Equations (1) through (3) with the constant, the first lag of the daily exchange rate change, the intervention volume and the large-volume intervention indicator variables, and the macro control variables included in the conditional mean model. Table 5 reports the results. As the two columns show, the (sample-specific) large-volume intervention indicator variable is insignificant in both estimations. This finding suggests the exchange rate effect per intervention unit (i.e. per USD spent on intervention purchases of JPY) associated with large-volume interventions is no different than the exchange rate effect per intervention unit of smaller interventions.

The previous finding does not imply that intervention volume does not matter. Rather, it suggests that the exchange rate effects of intervention can be described as linear in intervention volume. To further investigate if the exchange rate effects of intervention are properly captured by the linear intervention volume variable we add to the baseline model the previously defined interaction variable containing (signed) squared interventions. The estimation results with squared intervention volumes included are displayed in Table 6. As the table shows, the quadratic intervention term is insignificant in both sub-samples, thus we find no evidence that the exchange rate effects of intervention should be described by inclusion of a quadratic term.

\subsection{Threshold Analysis of Intervention Volume Effects}

We now turn to the results of the threshold analysis proposed by Hansen (2000) and described by Equations 4 and 5. Table 7 displays the results. The first column reports the results pertaining to the 1 April 1991 to 4 May 1995 sample. The first rows show that the coefficient estimates associated with small and large interventions are both of the wrong sign (consistent with the previously discussed results of the time-series analysis of the 1991 to 1995 sub-sample). The 
95\% confidence intervals are wide and overlapping, implying that the small and large intervention coefficient estimates are not significantly different. The threshold analysis indicates that the most likely intervention volume threshold value for this sub-sample is (absolute) USD 200.7 million, i.e. this is the sample-specific absolute intervention value demarcation point that defines small versus large interventions. The associated SupLR test statistic is 10.10 and, with a p-value of 0.112 , this most likely volume threshold is not significant at conventional levels.

The second column shows the results of the threshold analysis of the 5 May 1995 to 31 March 2004 sub-sample. The coefficient estimates associated with small and large interventions are both correctly signed and significant at $90 \%$ and $95 \%$, respectively (consistent with the previously discussed results of the time-series analysis of the 1991 to 1995 sub-sample). Again, the 95\% confidence intervals are overlapping to the extent that the small and large intervention coefficient estimates are statistically indistinguishable. The most likely intervention volume threshold value is (absolute) USD 1,400.93 million. This most likely threshold is highly insignificant with a SupLR test statistic of 5.20 and associated p-value of 0.632 .

The fact that none of the most likely intervention volume thresholds identified by the Hansen (2000) procedure is significant provides strong evidence that the exchange rate effect per intervention unit is largely constant and does not vary in a systematic fashion with intervention volume. This evidence is particularly compelling because, unlike no previous study of the volume effect of intervention, our threshold analysis does not rely on any priors regarding what constitutes a large or a small intervention. ${ }^{27}$

\footnotetext{
${ }^{27}$ It is important to point out that while all our findings strongly suggest that the exchange rate effects of intervention can be described as linear in intervention volume, there is nevertheless substantial variation across the exchange rate effects associated with individual intervention operations. To illustrate, each of the four most recent Japanese intervention episodes are all associated with coinciding JPY depreciations vis-à-vis the USD in the fairly narrow range of 2.2 to $3.1 \%$, yet the intervention volume of these episodes range from sales of USD 8.6 billion to sales of USD 116.3 billion.
} 


\subsection{Binary Choice Model Analysis of Determinants of Intervention Success}

We complement the investigation of volume effects with a broader assessment of which intervention characteristics, including intervention volume, determine the success of intervention by estimating the logit models described in Equations (6) and (7). Table (8) shows the results of the estimations pertaining to the direction criterion of success (Equation 6).

The first column shows that none of the intervention characteristics seem to influence the probability of success during the 1991 to 1995 period. This is unsurprising considering that the findings of our times-series analysis, as well as other studies, suggest that intervention during this period was generally ineffective. The second column shows that for the 1995 to 2004 subsample the intervention volume variable is a highly significant determinant of success, i.e. the larger the intervention volume, the higher the probability of intervention success. The intervention frequency variable, as measured by the number of business days since the last intervention (DSLI), is positive, thereby indicating that less frequent interventions are more likely to be successful. However, the frequency variable is insignificant at conventional levels. The variable capturing whether or not the market is aware of the intervention (DETECT) is highly insignificant. All coordinated interventions during the 1995 to 2004 sample are successful according to the direction criterion and, therefore, not included in the estimations. ${ }^{28}$

The estimations employing the smoothing criterion of success support identical conclusions. Table 9 displays the results. Intervention volume is, again, the only significant success determinant, and only for the 1995 to 2004 sample. Almost all coordinated interventions during the 1995 to 2004 sample are successful according to the smoothing criterion and, therefore, not included in the estimations.

\footnotetext{
${ }^{28}$ All coordinated interventions during the 1995 to 2004 sample occur before 1999.
} 
Overall, the results of this section confirm that intervention volume matters for the probability of intervention success. Furthermore, since coordinated intervention is perfectly correlated with intervention success according to the direction criterion and near-perfectly correlated with intervention success according to the smoothing criterion, coordination of intervention is also confirmed as a determinant for intervention success. While there is some indication that intervention frequency might play a role as well, no intervention characteristics other than volume and coordination significantly influence the probability of intervention success.

\subsection{Robustness}

In order to check the robustness of our results we redo the analysis using different sub-sample demarcation points, formally address the inherent issue of endogeneity, account for the fact that average turnover in the USD/JPY foreign exchange market has more than doubled during the two decades under study, and redo the logit model analysis on a sub-set of leaning against the wind operations only. ${ }^{29}$

First, we redo the entire analysis using the marginally significant second breakpoint identified by the Bai and Perron (1998) test at 26 September 2001. The findings stemming from analyzing the resulting three sub-samples are qualitatively identical to those previously discussed.

Second, we redo the entire analysis using residuals from intervention reaction function estimations as proxy measures of unexpected interventions that we use to replace actual intervention in order to reduce simultaneity bias of the coefficient estimates. Doing so follows

\footnotetext{
${ }^{29}$ Estimation results pertaining to the robustness section are available from the authors upon request.
} 
Humpage (1999) and others, and has become standard in daily data intervention studies. ${ }^{30}$ Not surprisingly, given that we expect endogeneity to be a limited concern in the context of assessing the relative importance of different intervention volumes, attempting to address the inherent issue of endogeneity renders all conclusions completely unchanged.

Third, we very crudely address the fact that average turnover in the USD/JPY foreign exchange market has more than doubled during the two decades under study and, as a result, one unit of intervention in absolute terms in, say, 1991, is relative to market depth smaller than one unit of intervention in absolute terms in, say, 2004. For each sub-sample we redo the analysis after measuring the daily intervention volume relative to the sample-specific average daily turnover in the USD/JPY spot market as reported by the BIS. ${ }^{31}$ We find that our results do not change from this sample-specific scaling of the intervention volume variable. ${ }^{32}$

Fourth, we redo the logit model analysis on a sub-set of leaning against the wind operations only in order to address the previously mention concern that both the direction and the smoothing criteria for successful intervention are problematic if intervention is "leaning with the wind. The logit model analysis of the sub-set of only leaning against the wind interventions yield qualitatively identical results as those described in the previous section with the minor exception that the frequency variable (DSLI) becomes marginally significant (at the $90 \%$ level) when the direction criterion is applied.

\footnotetext{
${ }^{30}$ See Fatum (2010) for details of this procedure and a discussion of its shortcomings. See Beine et al. (2009) and Ito and Yabu (2007) for recent studies focusing on the intervention reaction function of the Japanese monetary authorities.

31 According to the 1995, 2004, and 2010 BIS Triennial Central Bank Survey of Foreign Exchange and Derivatives Market Activity (statistical annex tables E.2), average daily USD/JPY spot market turnover was USD 87,661 million in 1995, USD 103,626 million in 2004, and USD 183,108 million in 2010. These statistics are used to measure the daily intervention volume relative to the sample-specific average daily turnover across the 1991 to 1995,1995 to 2004, and 2010 to 2012 samples, respectively.

${ }^{32}$ Clearly, this robustness check does not address the limitation that this and other intervention studies do not measure daily intervention volume relative to daily market depth. Unfortunately, it is not possibly to do so because daily data on market turnover does not exist.
} 


\section{Conclusion}

We investigate whether foreign exchange intervention volume matters for the exchange rate effects of intervention. Our investigation employs daily data on Japanese interventions spanning from April 1991 to April 2012 and various estimation techniques. Whether intervention volume matters is an issue of interest to authorities with a mandate to intervene as knowledge regarding the volume effects of intervention is necessary to make an informed decision regarding the amount with which to intervene. It is also an issue of academic interest since an understanding of the influence of intervention volume on the exchange rate effect of intervention may shed light on how intervention works.

Using time-series models of the day-to-day exchange rate change we first compare the explanatory power of intervention volume variables versus intervention indicator variables and show that intervention volume matters. We follow the existing intervention literature and estimate exchange rate time-series models with large-volume intervention indicator (slopeshifter) variables included. Our results show that large-volume interventions are no more effective than smaller interventions in an exchange rate effect per unit of intervention sense. We test for continuous non-linear intervention volume effects by including in our time-series models quadratic intervention terms and find no significant evidence of such volume effects.

A major shortcoming of the traditional approach used for assessing whether intervention volume matters is that tests evolve around arbitrarily imposed intervention volume thresholds. We address this fundamental concern by employing non-temporal breakpoint analysis. Doing so allows us to formally test whether intervention volume thresholds are present in our data without having to assume what such threshold levels might be. Our results suggest that no systematic structural breaks associated with intervention volume exist. 
We complement our time-series estimations and our non-temporal threshold analysis with a broader assessment of whether intervention volume along with other possible intervention characteristics, such as intervention frequency, market awareness of intervention, and coordination of intervention across central banks, influence the success of intervention. Our binary choice model estimations suggest that larger intervention volume and coordination both increase the probability of intervention success.

Our main finding is that intervention volume matters but only to the extent that the exchange rate effect per intervention unit is magnified in a linear sense by the larger intervention amount. This is of practical importance to the authorities in charge of deciding whether to intervene and in which amount. It is also a finding that adds to our understanding of how intervention works. Since intervention volume matters and non-linearities are absent, the exchange rate effects of intervention seem consistent with portfolio-balance effects. 


\section{References}

Anderson, David R.; Dennis J. Sweeney and Thomas A. Williams (2010): "Statistics for Business and Economics", Eleventh Edition, South-Western Cengage Learning.

Andrews, Donald W.K. (1993): “Tests for Parameter Instability and Structural Change with Unknown Change Point.” Econometrica 61, 821-856.

Andrews, Donald W.K. (1991): "Heteroskedasticity and Autocorrelation Consistent Covariance Matrix Estimation.” Econometrica 59, 817-858.

Bai, Jushan and Pierre Perron (1998). "Estimating and testing linear models with multiple structural changes.” Econometrica vol.66 no.1, 47-78

Baillie, Richard T. and Tim Bollerslev (1989). "The Message in Daily Exchange Rates: A Conditional Variance Tale.” Journal of Business and Economics Statistics 7, 297-305.

Beine, Michel and Oscar Bernal (2007): "Why Do Central Banks Intervene Secretly? Preliminary Evidence from the BoJ." Journal of International Financial Markets, Institutions and Money 17, 291-306.

Beine, Michel; Oscar Bernal; Jean-Yves Gnabo and Christelle Lecourt (2009): "Intervention Policy of the BoJ: A Unified Framework", Journal of Banking and Finance 33, 904-913.

Beine, Michel; Jérôme Lahaye; Sébastien Laurent; Christopher Neely and Franz C. Palm (2007): "Central Bank Intervention and Exchange Rate Volatility, Its Continuous and Jump Components”, International Journal of Finance and Economics 12, 201-224.

Beine, Michel and Arianne Szafarz (2002): "Size Matters: Central Bank Interventions and the Yen/Dollar Case", forthcoming in Brussels Economic Review.

Bordo, Michael D; Owen F. Humpage and Anna J. Schwartz (2011): “The Federal Reserve as an Informed Foreign Exchange Trader: 1973-1995.”, NBER Working Paper No. 17425.

Chen, Chin-Nan; Tsutomu Watanabe and Tomoyoshi Yabu (2009): "A New Method for Identifying the Effects of Foreign Exchange Interventions." Bank of Japan IMES Discussion Paper No. 09-E-06.

Dominguez, Kathryn M.E. and Jeffrey A. Frankel (1993). Does Foreign Exchange Intervention Work? Washington, D.C.: Institute for International Economics.

Fatum, Rasmus (2010): "Foreign Exchange Intervention When Interest Rates Are Zero: Does the Portfolio Balance Channel Matter After All?", Federal Reserve Bank of Dallas Globalization and Monetary Policy Institute Working Paper No. 57. 
Fatum, Rasmus and Michael M. Hutchison (2003): "Is sterilized foreign exchange intervention effective after all? An event study approach." The Economic Journal 113, 390-411.

Fatum, Rasmus and Michael M. Hutchison (2006). "Effectiveness of Official Daily Foreign Exchange Market Intervention Operations in Japan." Journal of International Money and Finance 25, 199-219.

Fatum, Rasmus and Barry Scholnick (2006): "Do Exchange Rates Respond to Day-to-Day Changes in Monetary Policy Expectations When No Monetary Policy Changes Occur?" Journal of Money, Credit and Banking 38, 1641-1657.

Fawley, Brett and Luciana Juvenal (2010). "Japan Reenters the Foreign Exchange Market." Federal Reserve Bank of St. Louis International Economic Trends, November 2010.

Hansen, Bruce E. (2000). "Sample Splitting and Threshold Estimation.” Econometrica 68, 575603.

Humpage, Owen F. (1999). "US Intervention: Assessing the Probability of Success." Journal of Money, Credit and Banking 31, 731-747.

Humpage, Owen F. (2003). "Government Intervention in the Foreign Exchange Market." Federal Reserve Bank of Cleveland Working Paper No. 03-15.

Ito, Takatoshi (2003). "Is Foreign Exchange Intervention Effective?: The Japanese Experience in the 1990s." In Paul Mitzen (ed.), Monetary History, Exchange Rates and Financial Markets, Essays in Honour of Charles Goodhart, Vol. 2, Edward Elgar, UK.

Ito, Takatoshi (2005). "Interventions and the Japanese Economic Recovery." International Economics and Economic Policy 2, 219-239.

Ito, Takatoshi and Tomoyoshi Yabu (2007). "What Promotes Japan to Intervene in the Forex Market? A New Approach to a Reaction Function." Journal of International Money and Finance 26, 193-212.

Iwata, Shigeru and Shu Wu (2008): "Foreign Exchange Interventions at Zero Interest Rates". Forthcoming in Macroeconomic Dynamics.

Kim, Suk-Joong and Anh Tu Le (2010): "Secrecy of Bank of Japan's Yen Intervention: Evidence of Efficacy from Intra-Daily Data." Journal of The Japanese and International Economies 24, 369-394.

Kim, Suk-Joong and Jeffrey Sheen (2006): "Interventions in the Yen-Dollar Spot Market: A Story of Price, Volatility and Volume", Journal of Banking and Finance 30, 3191-3214. 
Marsh, Ian W. (2011). "Order Flow and Central Bank Intervention: An Empirical Analysis of Recent Bank of Japan Actions in the Foreign Exchange Market”. Journal of International Money and Finance 30, 377-392.

Neely, Christopher J. (2005). “An Analysis of Recent Studies of the Effect of Foreign Exchange Intervention.” Federal Reserve Bank of St. Louis Review 87, 685-717.

Neely, Christopher J. (2008): “Central Bank Authorities' Beliefs about Foreign Exchange Intervention." Journal of International Money and Finance 27, 1-25.

Neely, Christopher J. (2011). “A Foreign Exchange Intervention in an Era of Restraint.” Federal Reserve Bank of St. Louis Review 93, 303-324.

Perron, Pierre and Yohei Yamamoto (2011). "Using OLS to estimate and test for structural changes in models with endogenous regressors." unpublished manuscript

Sarno, Lucio and Mark P. Taylor (2001): "Official Intervention in the Foreign Exchange Market: Is It Effective and, If So, How Does It Work?” Journal of Economic Literature 39, 839-868.

Taylor, John B. (2006). "Lessons from the Recovery from the "Lost Decade" in Japan: The Case of the Great Intervention and Money Injection." Background Paper for the International Conference of the Economic and Social Research Institute Cabinet Office, Government of Japan.

White, Hal (1980). "A heteroskedasticity-consistent covariance matrix estimator and a direct test for heteroskedasticity." Econometrica 48, 817-838. 


\begin{tabular}{|c|c|c|c|c|}
\hline 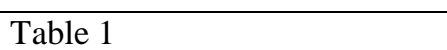 & \multicolumn{4}{|c|}{ Official Intervention in the USD/JPY Market April 1991 to April 2012} \\
\hline & $\begin{array}{l}\text { 1 Apr } 1991 \text { to } \\
25 \text { Apr } 2012\end{array}$ & $\begin{array}{l}\text { 1 Apr } 1991 \text { to } \\
4 \text { May } 1995\end{array}$ & $\begin{array}{l}5 \text { May } 1995 \text { to } \\
31 \text { Mar } 2004\end{array}$ & $\begin{array}{l}\text { 1 Sep } 2010 \text { to } \\
25 \text { Apr } 2012\end{array}$ \\
\hline Total Intervention Days & 352 & 165 & 179 & 8 \\
\hline Cumulated Amount & 830,674 & 82,082 & 541,669 & 206,923 \\
\hline Average Daily Amount & 2,360 & 497 & 3,026 & 25,865 \\
\hline Maximum Daily Amount & 103,265 & 3,901 & 20,317 & 103,265 \\
\hline Minimum Daily Amount & 1 & 25 & 1 & 2,598 \\
\hline Standard Deviation & 6,806 & 502 & 3,204 & 36,487 \\
\hline $\begin{array}{l}\text { Average Daily Amount } \\
\text { Relative to Average Daily } \\
\text { USD/JPY Spot Market } \\
\text { Turnover }\end{array}$ & - & $0.57 \%$ & $2.92 \%$ & $14.13 \%$ \\
\hline Coordinated Intervention Days & 23 & 17 & 5 & 1 \\
\hline Detected Intervention Days & 214 & 96 & 110 & 8 \\
\hline
\end{tabular}

\section{NOTES:}

(a) Daily Japanese intervention data obtained from the Japanese Ministry of Finance data bank. Daily US intervention data obtained from the Federal Reserve Bank of St. Louis data bank (FRED)

(b) All amounts are in millions of USD. Average Daily Amount and Standard Deviation refer to intervention days only

(c) According to the 1995, 2004, and 2010 BIS Triennial Central Bank Survey of Foreign Exchange and Derivatives Market Activity (statistical annex tables E.2) average daily USD/JPY spot market turnover was USD 87,661 million in 1995, USD 103,626 million in 2004, and USD 183,108 million in 2010. These statistics are used to calculate the average intervention to market turnover numbers across the 1991 to 1995, 1995 to 2004, and 2010 to 2012 samples, respectively. The BIS statistics are available at http://www.bis.org. 


\begin{tabular}{|c|c|c|c|c|}
\hline Table 2 & \multicolumn{4}{|c|}{ The USD/JPY Rate April 1991 to April 2012} \\
\hline & $\begin{array}{l}1 \text { Apr } 1991 \text { to } \\
25 \text { Apr } 2012\end{array}$ & $\begin{array}{l}\text { 1 Apr } 1991 \text { to } \\
\text { 4 May } 1995\end{array}$ & $\begin{array}{l}5 \text { May } 1995 \text { to } \\
31 \text { Mar } 2004\end{array}$ & $\begin{array}{l}1 \text { Sep } 2010 \text { to } \\
25 \text { Apr } 2012\end{array}$ \\
\hline Start of Period & 0.00713 & 0.00713 & 0.01190 & 0.01184 \\
\hline End of Period & 0.01229 & 0.01196 & 0.00959 & 0.01229 \\
\hline Percent Change & 72.37 & 67.74 & -19.41 & 3.80 \\
\hline Mean & 0.00919 & 0.00887 & 0.00869 & 0.01244 \\
\hline Max & 0.01319 & 0.01233 & 0.01207 & 0.01319 \\
\hline Min & 0.00680 & 0.00705 & 0.00680 & 0.01165 \\
\hline Standard Deviation & 0.00131 & 0.00115 & 0.00086 & 0.00042 \\
\hline & & & & \\
\hline
\end{tabular}

NOTES:

(a) Data Source: Global Financial Data (New York close daily quotes) 


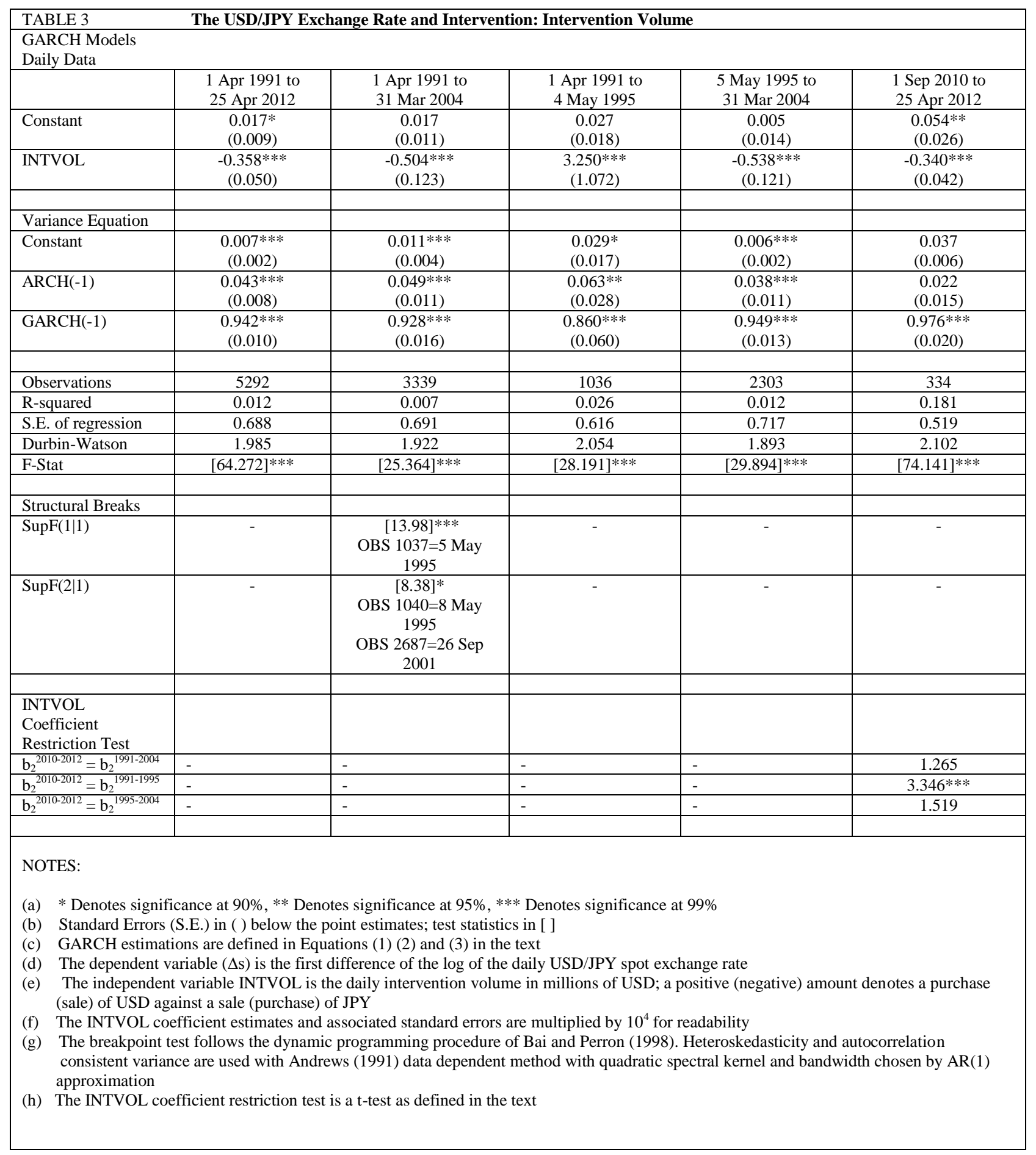









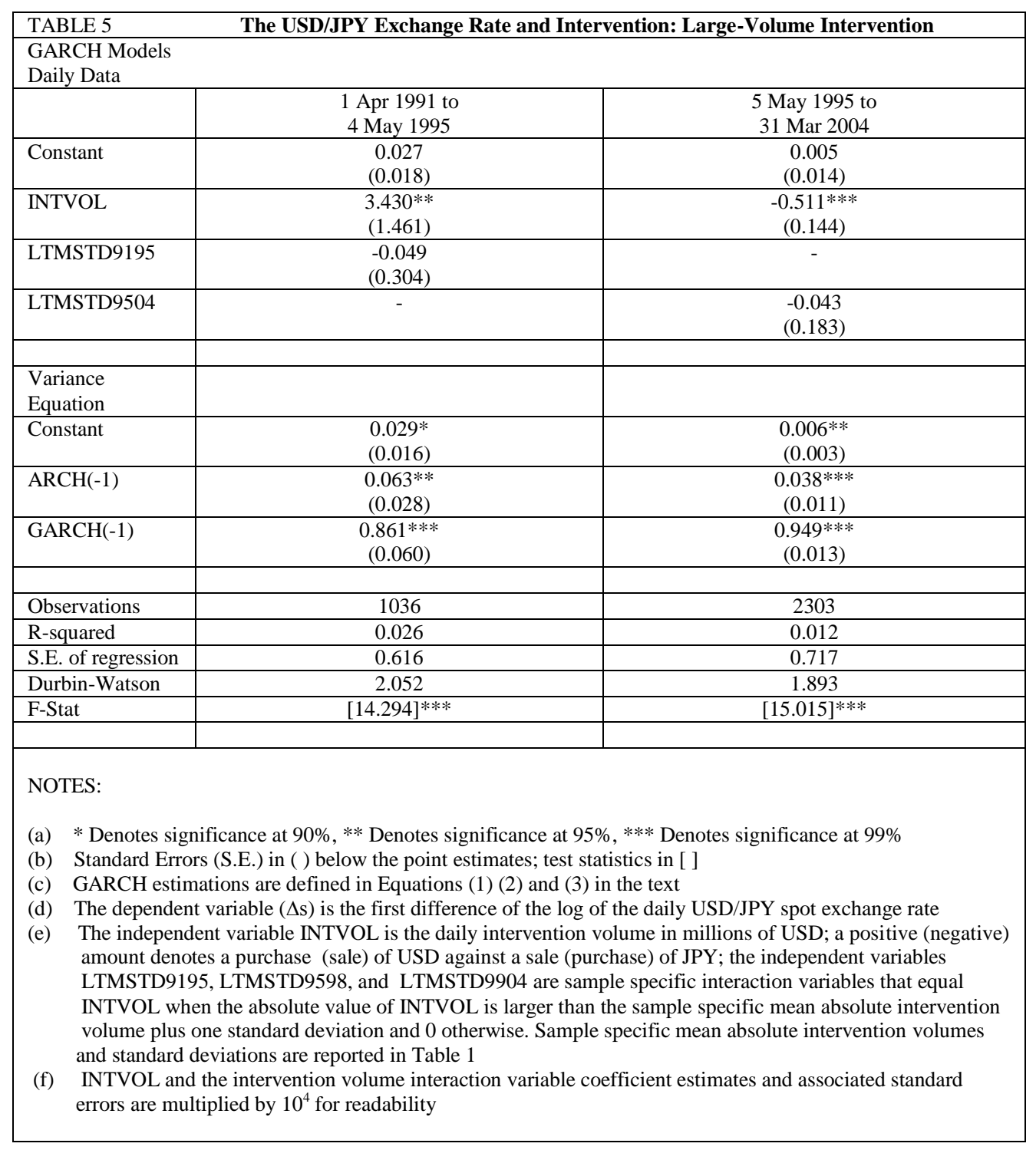




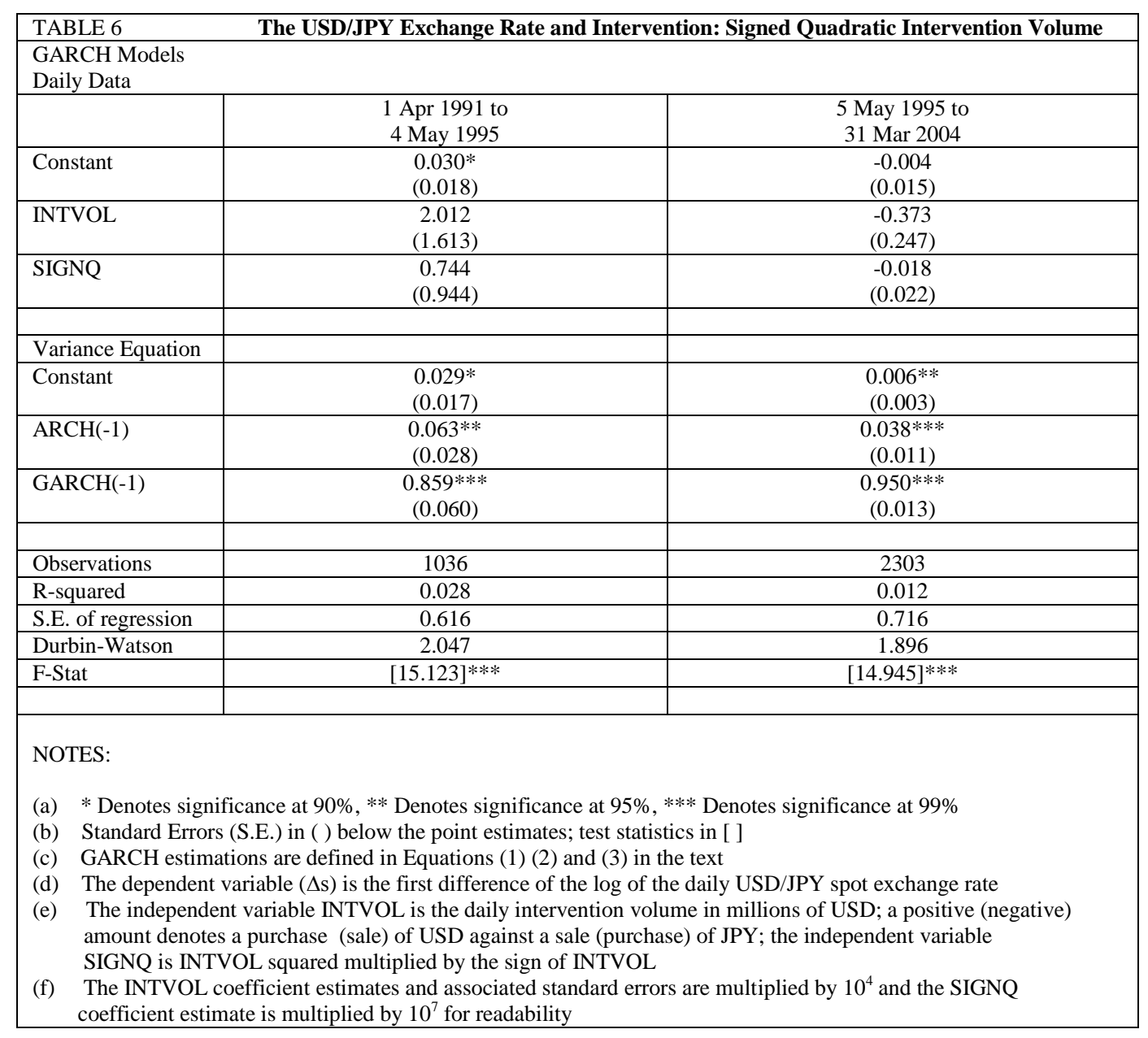









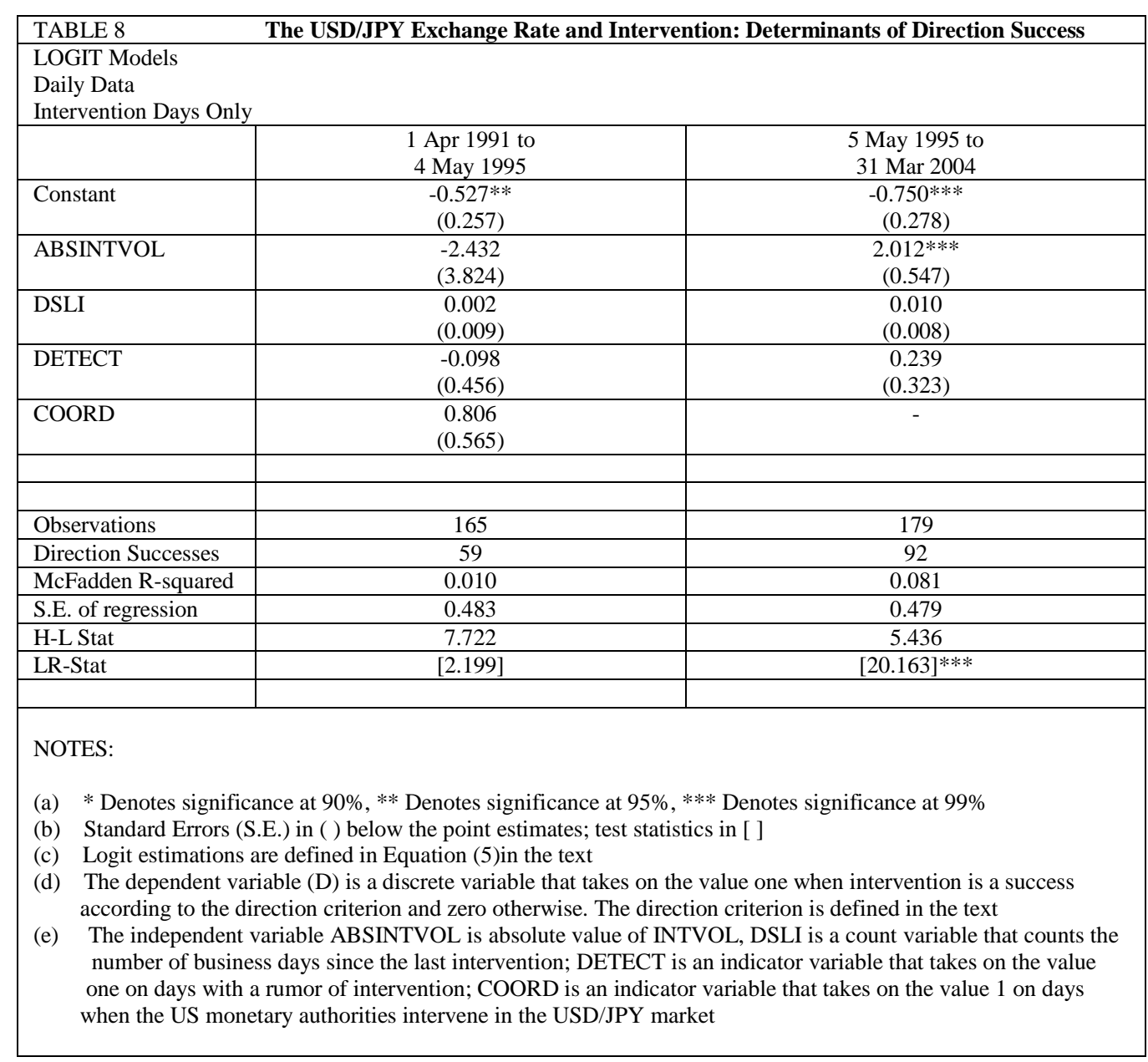




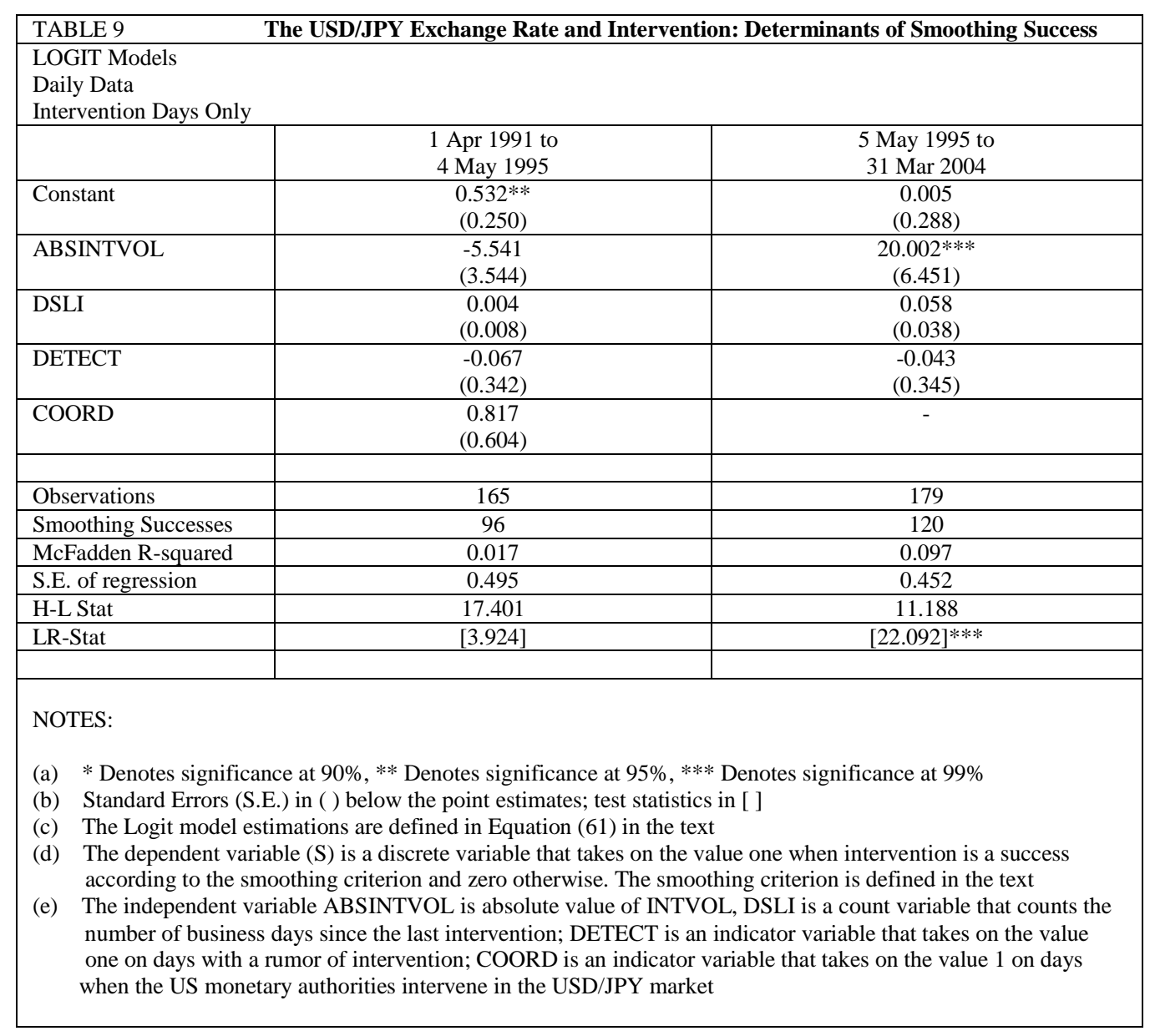

